\title{
Intra-male variability of its communication signal in the weakly electric fish, Marcusenius macrolepidotus (South African form), and possible functions
}

\author{
Susanne Hanika ${ }^{1)}$ \& Bernd Kramer \\ (Zoological Institute of the University, Regensburg, Germany)
}

(Accepted: 27 January 2005)

\section{Summary}

Mormyrid fish generate electric organ discharges (EODs) continuously for electrocommunication and electrolocation. EOD pulse waveforms are, within species limits, individually specific and usually stable over long periods of time. We conducted playback experiments with the African weakly electric snoutfish, Marcusenius macrolepidotus (South African form), or bulldog fish, originating from the Incomati River System in South Africa. Previous field observations had shown an increase of male, but not female, EOD pulse duration with body size. Therefore, we tested the hypothesis that EOD pulse duration might be of relevance in territorial male-male contests. We determined whether or not aggression scores recorded for males kept in adjacent aquarium compartments depended on playback EOD duration. Playback EODs had been pre-recorded either from familiar or from unfamiliar conspecific males, and varied naturally in duration.

As independently confirmed in all five experimental subjects, the attack rate on a dipole model playing back strangers' EODs from the territorial boundary increased significantly with stimulus EOD pulse duration (that varied from $329 \mu$ s to $975 \mu$ s in our field sample of playback EODs). This result was confirmed when one specific EOD, the duration of which was artificially decreased or increased, was used for playback, showing that in male M. macrolepidotus EODs of so long duration signal a greater threat than EODs of shorter duration. Therefore, EOD duration may be relevant for males in the assessment of their rivals' size and fighting potential. Moreover, experimental subjects confronted with familiar playback EODs showed a significantly lower rate of attack than expected for unfamiliar EODs of the same duration. An individual familiar neighbour's EOD evoked a significantly weaker attack rate when played back from the regular rather than from the opposite territorial boundary. These observations are compatible with the 'dear enemy' hypothesis.

\footnotetext{
1) Corresponding author's address: Zoological Institute of the University, 93040 Regensburg, Germany; e-mail address: Susanne.Hanika@biologie.uni-regensburg.de
}

(C) Koninklijke Brill NV, Leiden, 2005

Behaviour 142, 145-166

Also available online - 
Keywords: electrocommunication, electric organ discharge, neighbour recognition, playback, dear enemy phenomenon, intrasexual selection.

\section{Introduction}

Weakly electric mormyrid fish of Africa use their electric organ discharges (EODs) for electrolocation and electrocommunication (reviews: Kramer, 1990, 1996; Moller, 1995; Turner et al., 1999). The waveform of their EOD pulses carries sufficient information for species discrimination, it may even be individually specific and in certain species sexually dimorphic (Kramer, 1997a, b). In Marcusenius macrolepidotus (South African form), a mormyrid fish from the South African Incomati River system, a statistically significant difference between male and female EOD duration was found, and male, but not female, EOD duration increased with body length (Kramer et al., 1998, in prep.).

The identity of male communication signals may be relevant in various contexts. For females, male EODs may indicate the location of their mate, his reproductive status, or his fitness, but male EODs may also serve in intrasexual communication. Male communication signals in the use of assessment of rivals is a topic that has attracted far less attention than intersexual communication (ten Cate et al., 2002), even though the influence on the evolution of variable male signals may be great. Males could assess an opponent's body size and fighting ability (e.g., Davies \& Halliday, 1978; Clutton-Brock \& Albon, 1979) when the communication signals are correlated to fitness or size, the latter found in M. macrolepidotus' (South African form) EODs. Pilot experiments suggested a relationship between playback EOD duration and male aggression (that was directed at a dipole fish model). Therefore, we studied the dependency of the males' attack rate on playback EOD duration in more detail. We chose electrical playback to exclude all other cues, such as chemical, olfactory, acoustical or visual. We used M. macrolepidotus (South African form) because of their territorial behaviour in captivity (Werneyer \& Kramer, 2002; SH, pers. obs.), the individually distinct EOD waveforms (Kramer et al., 1998, in prep.), and the readiness of male M. macrolepidotus to attack active dipoles playing back conspecifics' EODs.

Discrimination of conspecific communication signals may also function in kin recognition (review: Hepper, 1991), colony member recognition (review: Hare, 1994), and neighbour recognition (review: Temeles, 1994), as 
documented in a wide variety of species. Individuals that recognise neighbours, resulting in more or less settled affairs, may be able to reduce their aggressive responses to these animals and would require less time and energy for territorial defence (Chellappa \& Huntingford, 1989; Thorpe et al., 1995). This effect is called the 'dear enemy' phenomenon (Fisher, 1954; for reviews of neighbour-stranger discrimination see Ydenberg et al., 1988; Temeles, 1994). The 'dear enemy' phenomenon was observed in many different species, including cichlid fish (Peeke et al., 1971; Leiser \& Itzkowitz, 1999), trout (Johnsson, 1997; Höjesjö et al., 1998), swordtails (Morris et al., 1995), and the gymnotiform Gymnotus carapo (McGregor \& Westby, 1992).

Conditions necessary for neighbour recognition are (1) physical differences in signals used for communication, (2) sufficient sensory discrimination in the receiver, and (3) communication signals of sufficient constancy. All these conditions seem to be met in mormyrid fish: (1) in spite of EODs of very short duration (often $<1 \mathrm{~ms}$ ), waveform parameters vary considerably between individuals (for example, Lücker \& Kramer, 1981; Bratton \& Kramer, 1988; Crawford, 1992; for M. macrolepidotus (Upper Zambezi), Kramer, 1997a). (2) The mormyrid species Pollimyrus adspersus discriminates between its short intraspecific (or synthetic) playback EODs, even when only slightly different (Graff \& Kramer, 1992; Paintner \& Kramer, 2003). The microsecond-resolution shown by these fish demonstrates a much higher sensitivity than required for species recognition, and makes sense only for the much more difficult task of intraspecific discrimination. (3) Whereas the intervals between EOD pulses are highly variable and specific for the social context (Scheffel \& Kramer, 2000, in press; Werneyer \& Kramer, 2002), EOD waveforms are usually constant over long periods of time (Kramer \& Westby, 1985; Bratton \& Kramer, 1988; Crawford, 1991).

Therefore, our second aim was to determine whether an individual mormyrid fish would reduce its aggression against neighbours compared to strangers on the basis of individual EOD waveform. According to theory, a fish is expected to respond less aggressively to a neighbour's than to a stranger's EODs. 


\section{Methods}

\section{Animals and animal care}

All fish used in the present study originate from the Incomati River System (South Africa, Mpumalanga, 25 latitude South) with its two tributaries, the Sabie River (Kruger National Park; standard fish length 12-15 cm) and the Crocodile River (Stentor Estates near the town of Kaapmuiden; standard fish length 17-20 cm). According to present taxonomy these fish are Marcusenius macrolepidotus (Peters, 1852) because Gnathonemus pongolensis Fowler, 1934 (that became M. pongolensis (Fowler, 1934) by Taverne's (1971) revision of the genus Gnathonemus) was synonymized with that species. As there is controversy about the merit of this synonymization, we refer to our fish as M. macrolepidotus 'South African form' at present. EODs used for playback were recorded either in the field (B.K., Incomati River System; 'Stimulus' fish S1-S16) or in the laboratory (fish S17-S20) (no differences between field recorded and lab recorded EOD waveforms, B.K., unpubl. results). Fish S17-S20 had been housed separately from the experimental subjects from arrival in the lab on and were not used as experimental subjects. The experimental subjects (E1-E5) were kept in the same tank as their neighbours (N1-N10).

The artificially controlled light: dark period was $12: 12 \mathrm{~h}$, the water temperature $23^{\circ} \mathrm{C}$ and water conductivity $100 \mu \mathrm{S} / \mathrm{cm}$. Fish were fed frozen bloodworms (chironomid larvae) five times per week, usually after the experiments. Experimental aquaria $(210 \times 60 \times 50 \mathrm{~cm}$ high $)$ were divided into three compartments of equal size using two plastic-mesh partitions that allowed electrical and limited visual interaction (Figure 1). In the centre of each compartment a porous pot was placed for shelter. The plastic mesh partitions prevented the fish from inflicting damage to each other. All males showed territorial behaviour. Especially at the beginning of the dark cycle, fish patrolled the boundaries of their territories and engaged in behaviour described as aggression acts by Werneyer \& Kramer (2002): (1) the predominant behaviour was 'parallel swimming' of both neighbours along their common plastic mesh boundary, (2) but also 'antiparallel display' (remaining closely together in a head-to-tail position; however, circling — as would occur in free water - was impossible because of the plastic mesh partition), or (3) trying to attack each other through the plastic mesh. 


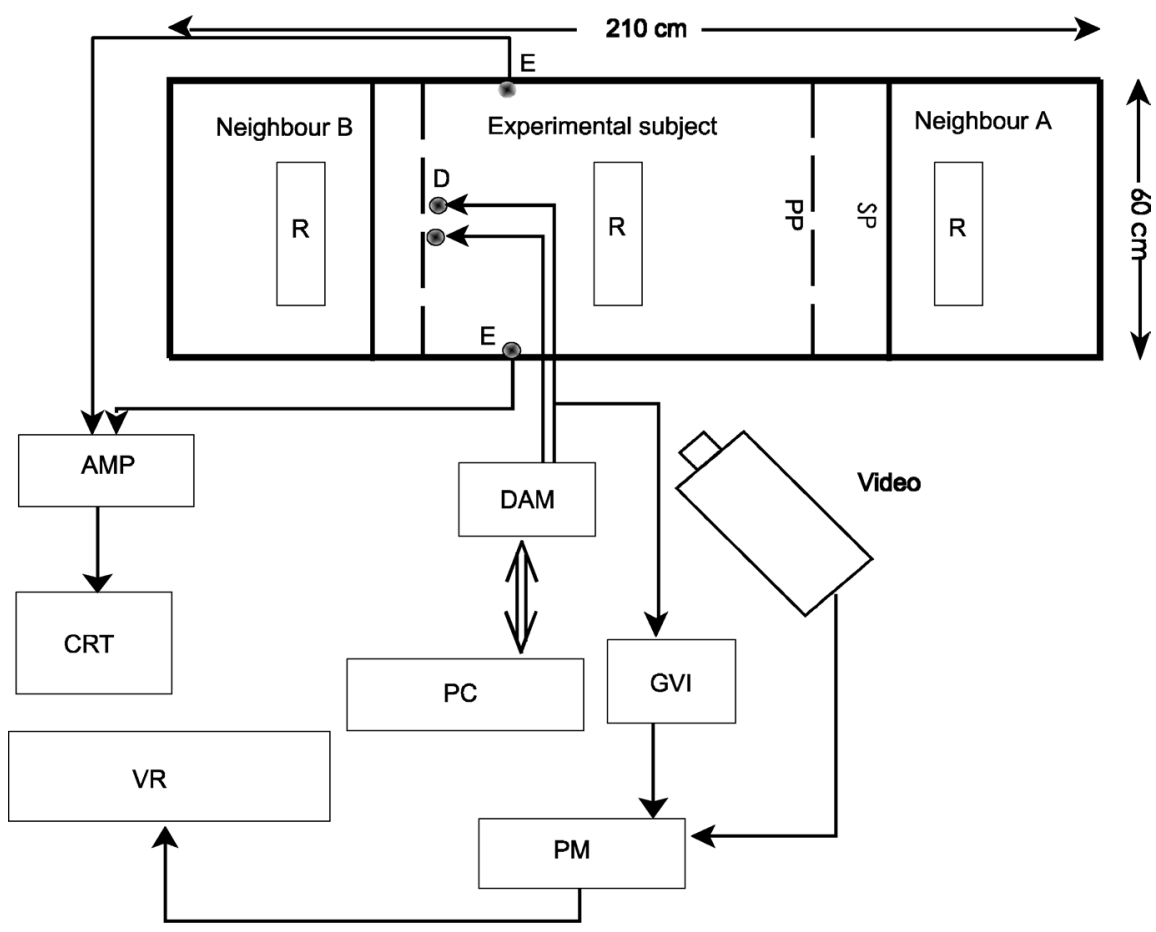

Figure 1. Set-up used for playback experiments with Marcusenius macrolepidotus. AMP, differential amplifier; CRT, oscilloscope; D, stimulus dipole; DAM, digital-to-analog converter with memory; E, electrode; GVI, full-way rectifying and summing amplifier with Schmitt trigger; PC, computer; R, resting position of fish; PP, plastic-mesh partition; SP, solid plastic partition; Video, videocamera; PM, pulse marker; VR, videotape recorder.

One out of six males available as experimental subjects did not engage in aggressive encounters with its neighbours and never responded to playback of EODs in any noticeable way ( $N=24$ trials). Therefore, we excluded this fish from further study.

Experiments were performed at reduced light intensity during daytime (8 lux, measured under water at the aquarium bottom) because fish became less active at higher light intensities. During all experiments the experimental subjects were electrically and visually shielded from both neighbours by two solid plastic partitions, in addition to the plastic-mesh partitions. The solid plastic partition attenuated electric field intensity, as measured with a 1$\mathrm{cm}$ dipole, below detection level (measurement of EOD field potentials, see below). No behavioural responses of neighbours thus isolated to playback EODs from an experimental subject's territory were observed. However, 
on removal of the solid plastic partition both fish immediately displayed vigorous parallel swimming at the plastic-mesh partition for a few minutes.

\section{Stimuli}

Given the high stability of EOD waveforms (Kramer \& Westby, 1985; Bratton \& Kramer, 1988), a single EOD represents all EODs of an individual mormyrid fish at a constant water temperature and conductivity (Bratton \& Kramer, 1988; Kramer \& Kuhn, 1993). In the laboratory, EODs were recorded at $23^{\circ} \mathrm{C}$ water temperature and $100 \mu \mathrm{S} / \mathrm{cm}$ conductivity, using lowimpedance carbon electrodes. EODs were differentially amplified $(10 \times ; 0.2$ $\mathrm{Hz}-100 \mathrm{kHz}$ ), digitised (Tektronix TDS oscilloscope 420, sampling rate 500 $\mathrm{kHz}, 13$ bit vertical resolution) and stored on computer disk. Conditions of EOD recording in the field were similar (details: Kramer \& Van der Bank, 2000). EOD files were downloaded onto a microprocessor-controlled digitalto-analog converter with memory and differential output amplifier (Figure 1, DAM; Kramer \& Weymann, 1987). The device had an amplitude resolution of 8 bit at each amplification step and 2048 points per trace at a sampling rate of $500 \mathrm{kHz}$.

Field potentials generated by the stimulus dipole were measured at the experimental subject's resting position by a pair of glassy carbon electrodes (Sigradur $\mathrm{G}$ electrodes, rod diameter $1 \mathrm{~mm}$, rod length $60 \mathrm{~mm}$, insulated except for $10 \mathrm{~mm}$ at the tips) with an inter-electrode separation of $1 \mathrm{~cm}$. The peak-to-peak amplitude of DAM-generated EODs, as measured at the resting position of the experimental subject, corresponded to the EOD amplitude generated by fish N1 (SL approx. $14 \mathrm{~cm} ; 2.5 \mathrm{mV}_{\mathrm{P}-\mathrm{P}} / \mathrm{cm}$ ) measured at the same position, and was used in all experiments. The other neighbour fish used in these experiments generated similar EOD amplitudes.

As already described (Kramer et al., 1998, in prep.; Werneyer \& Kramer, 2002), EOD waveforms of all Marcusenius macrolepidotus specimens from South Africa used in the present study were biphasic, with a head-positive phase followed by a negative one (Figure 2). EOD duration was estimated using the software package Famos (IMC, Berlin). We used a $2 \%$ threshold criterion relative to the $\mathrm{P}$-phase peak-amplitude for estimating onset and termination of an EOD waveform.

For playback, we varied the duration of one male's EOD by artifically increasing or decreasing the sampling rate using FAMOS (fish S20). 


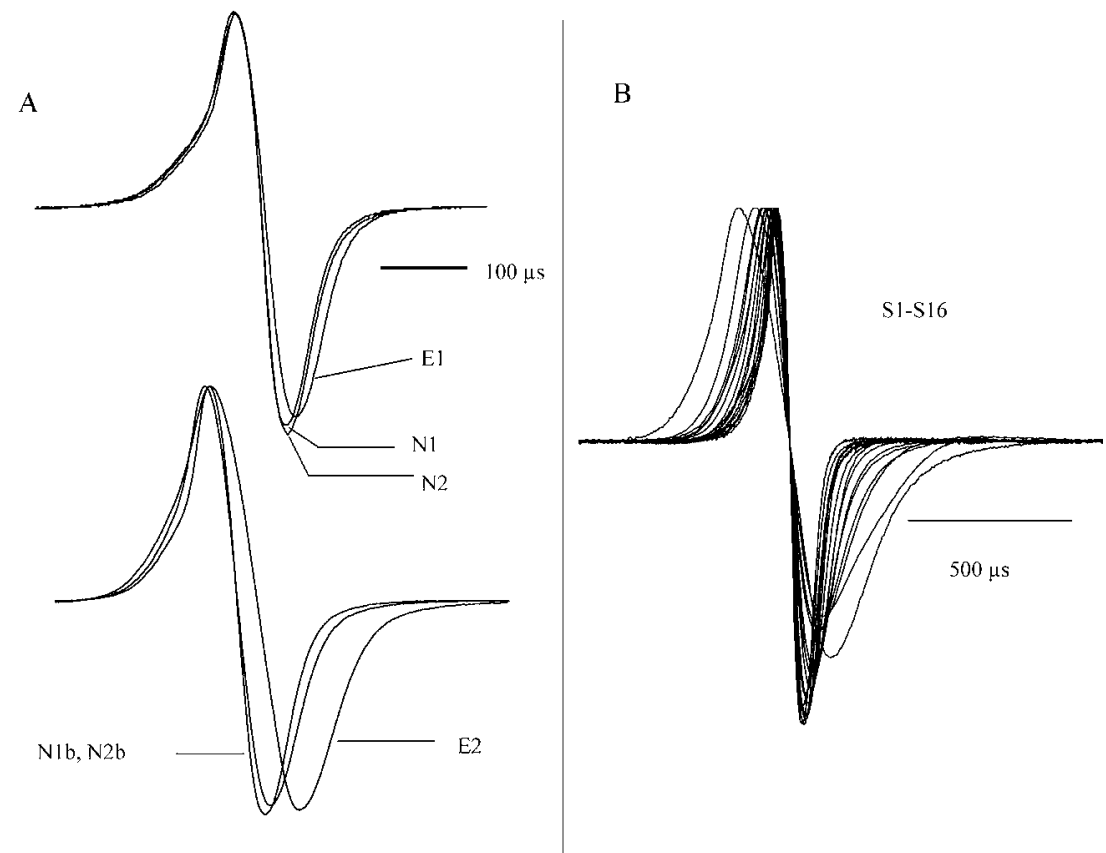

Figure 2. Electric organ discharge (EOD) waveforms recorded from (A) the experimental subjects (E1, E2), their neighbours (N1, N2, N1b, N2b), and (B) 'stranger' fish (S1-S16). Superimposed EODs are from fish kept in the same tank. The EOD waveforms of N1 and $\mathrm{N} 2$ had increased in duration after a 5 months' break and were then termed N1b and N2b, respectively. Voltage over time (baseline $=0 \mathrm{~V}$, head positivity is upwards), waveforms generated by the DAM. All experimental subjects and neighbours were male. Time in $\mu \mathrm{s}$ as indicated by time bars.

\section{Stimulus dipole}

EODs chosen for playback were presented using a stimulus dipole consisting of a pair of carbon rod electrodes $(5 \mathrm{~mm}$ diameter, insulated except for $1 \mathrm{~cm}$ at the tips) that were orientated vertically and separated by $30 \mathrm{~mm}$. Attacks directed at an electrically active dipole are well-known in mormyrids, even though the dipole bears no visual, mechanical or olfactory resemblance to an electric fish (Kramer, 1979; Schluger \& Hopkins, 1987). The dipole electrode tips were about $5 \mathrm{~cm}$ above the aquarium bottom, and the dipole was placed in parallel and right next to the boundary shared with a neighbour (Figure 1). 


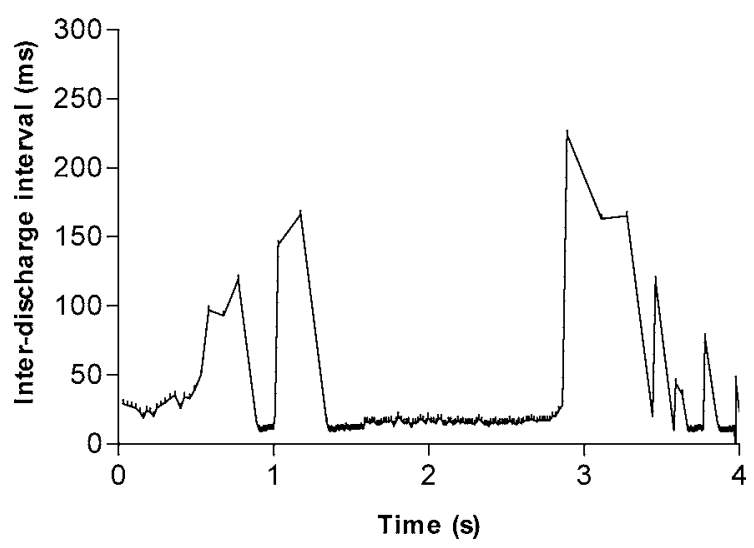

Figure 3. Inter-discharge interval (IDI) pattern of a male M. macrolepidotus over time. Points connected by lines to better show trends. IDI recorded of a male engaging in a highintensity agonistic behaviour (parallel swimming).

Inter-discharge interval (IDI)

Whereas EOD waveforms of individual mormyrid fish vary little over time, inter-discharge intervals vary greatly from moment to moment, and show strong correlation with social context (e.g., Bauer \& Kramer, 1974; Kramer, 1978; review Carlson, 2002). The behavioural response of a mormyrid fish to playback of stimulus pulses may depend on the pattern of inter-discharge intervals used for playback (Kramer, 1979; Teyssèdre \& Serrier, 1986). Stimulus EODs presented at an IDI pattern that was recorded from a resting fish evoked only weak responses from the experimental subject, whereas the high-discharge rate pattern recorded from a fish displaying parallel swimming often evoked vigorous attacks on the dipole model (up to 65 butts/30 s). For our playback experiments a single IDI pattern was used, a pattern recorded during an aggressive male's parallel swimming (Figure 3 ). This is a typical behaviour for a pair of male fish at their common territory boundary (Werneyer \& Kramer, 2002). The IDI sequence used lasted 4 s and was repeated in an 'infinite loop' during the 30 -s stimulation period. The IDI pattern of Fig. 3 starts with intervals of $20-40 \mathrm{~ms}$, followed by shorter intervals (10-20 ms) that are interrupted for about 4 times by long intervals (Figure 3 ). Stimulus EODs presented at this IDI pattern evoked vigorous attacks on the dipole fish model, especially at the beginning of a test series. 


\section{Protocol}

Operated by the experimenter, a host computer gave the instructions necessary to select an EOD waveform from DAM memory, and to start and stop the stimulation. A stimulus presentation lasted $30 \mathrm{~s}$, followed by a 2 min period of rest. The sequence of presentation of 2 to 5 different stimulus EOD waveforms used for a particular experiment (hereafter test) was determined using a randomised blocks design (Cochran \& Cox, 1968: Table 15.7). Responses of territorial M. macrolepidotus to the playback of EODs were observed before, during and after playback. We videotaped the whole test for subsequent analysis. Every stimulus pulse generated by the DAM was recorded on the audiotrack of the videotape and also as a black line on the left side of the video image.

Attack rate was measured as the number of butts directed at the dipole during the 30-s stimulation period. Other kinds of evoked responses, such as the total time spent near the territory boundary during playback, or the latency from stimulus onset to an experimental subject's arrival at the dipole, were not related to EOD waveform: fish usually swam to the dipole immediately and usually remained there for the whole stimulation period.

\section{Neighbour-stranger playbacks}

These experiments were designed to determine whether or not resident males discriminate between EODs of familiar neighbours and unfamiliar strangers. All specimens of $M$. macrolepidotus used as 'strangers' had been kept in separate communal tanks from arrival in the laboratory. For neighbour-stranger comparison tests, a stimulus dipole was positioned just 'inside' and close to the regular shared boundary of an experimental subject, a position that should evoke responses from the territory holder both for strangers' and neighbours' stimulus EODs. To confirm the influence of EOD duration on attack rate we also used EODs of artificially increased or reduced duration. The original EOD had a duration of $498 \mu$ s which was either reduced or increased within the limits of 213 to $765 \mu \mathrm{s}$. An increase in duration was achieved by slowing down the sampling rate of the A/D converter; duration decrease by resampling of the EOD waveform using FAMOS, generating an EOD with fewer points. The waveform parameter ratios - such as the $\mathrm{P} / \mathrm{N}$ ratio and ratio of areas - remained constant for all modified EODs. In an additional experiment, the dipole position was changed. Neighbours' 
EODs were played back either from the regular ('correct') or the opposite ('incorrect') boundary. Experiments were performed with fish that had been neighbours for 1-4 weeks and were repeated after 2-5 months.

\section{Results}

\section{Dependency of attack rate on stimulus EOD duration}

During all experiments of this study, the experimental subjects were electrically shielded from both neighbours' EODs by solid plastic partitions. All five experimental subjects ignored the stimulus dipole unless a signal was on the electrodes. Upon playback of EODs at the territorial boundary, all fish left their shelter, swam to the dipole at the territory boundary and attacked it. We never observed attacks on the dipole in the 2-min rest period between tests, but especially at the beginning of a test series, fish remained at the territory boundary even after stimulation had stopped. This latter behaviour occurred more often when stimulus EODs had evoked vigorous attacks than when low rates of attacks had been observed.

Attack rate increased significantly with the duration of strangers' EODs (all unmodified) in all three experimental subjects E1-E3 (Figure 4 A-C; Table 1). We repeated this part of the study with two additional experimental subjects, E4 and E5, using the full range of stimulus EOD durations found in this species (Figure $4 \mathrm{D}$ and E). A significant increase of attack rate with EOD duration was also confirmed in these fish $(p<0.01$ for each individual separately, with at least $45 \%$ of the variation explained by EOD duration;

Figure 4. (A-E). Rates of attack on a dipole model evoked in the experimental subjects E1 to E5. For EODs of strangers ( $\mathbf{\square})$, attack rate (butts/30 s) increased with EOD duration (least-squares regression line, means with $\pm 95 \%$ confidence intervals). A familiar neighbour's EOD $(\triangle)$ of a specified EOD duration evoked weaker responses than expected for an unfamiliar EOD of the same duration ( $\square$, extrapolation necessary for fish E3). $N=55$ tests per fish and data point (A-E). (F) As (A-E), but attack rates shown by fish E1-E3 increased with duration of playback EOD (that had been recorded from the unfamiliar fish S20 and played back unmodified as well as artificially modified in duration). Attack rates for natural, unmodified playback EOD, white symbols; for artificially modified EODs, black symbols. Natural EOD duration, $498 \mu$ s; artificially modified EOD duration values, 213, 300, 550, 765 $\mu \mathrm{s}$. For clarity, attack rates for the latter were slightly displaced horizontally to avoid the clutter caused by overlapping standard error ranges. $N=45$ tests per fish per data point (see 

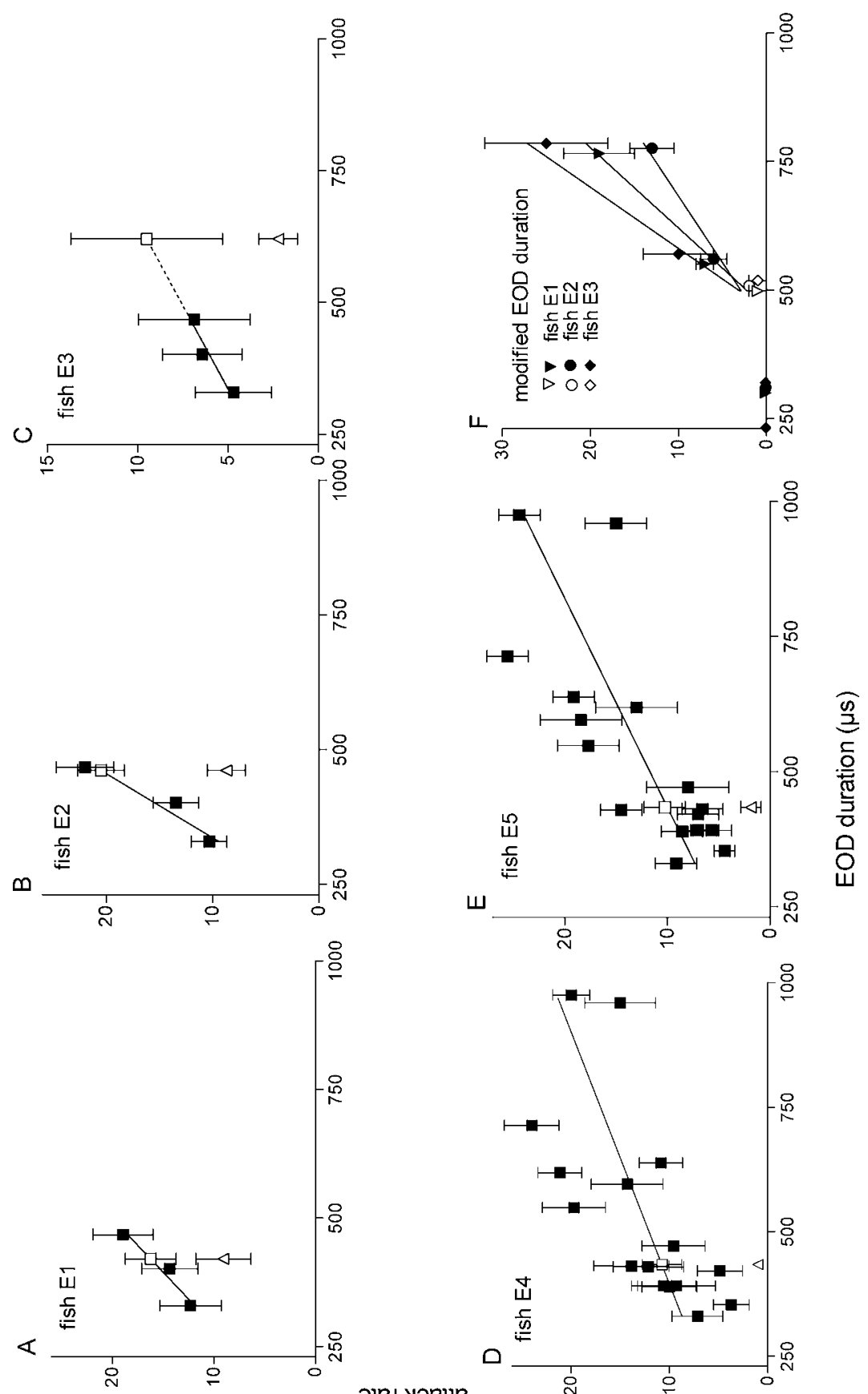

8
음
옹
in
유

әуеג үоене

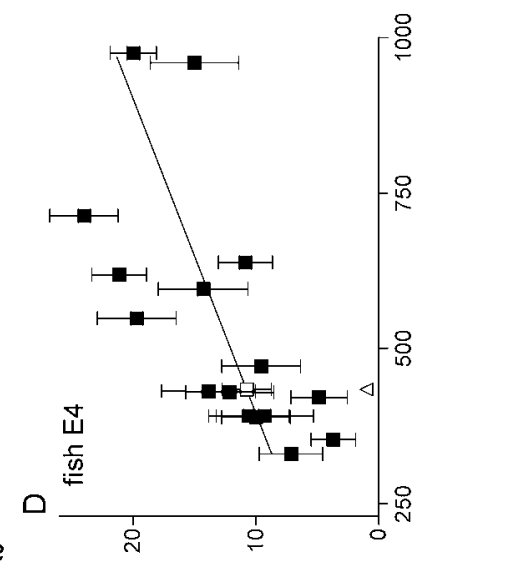


Table 1. Linear regression of the dependency of attack rate on stimulus EOD pulse duration

\begin{tabular}{lccllll}
\hline $\begin{array}{l}\text { Exp. } \\
\text { subject }\end{array}$ & Slope $\pm \mathrm{SD}$ & Y-intercept $\pm \mathrm{SD}$ & $r^{2}$ & $F$ & df & $p$ \\
\hline E1 & $0.045 \pm 0.01$ & $-2.1 \pm 6.8$ & 0.45 & 7.1 & 163 & 0.0085 \\
E2 & $0.01970 \pm 0.005$ & $-11 \pm 5.2$ & 0.45 & 14 & 163 & 0.003 \\
E3 & $0.086 \pm 0.011$ & $-19 \pm 4.6$ & 0.27 & 56.8 & 163 & 0.001 \\
E4 & $0.025 \pm 0.006$ & $-1.2 \pm 3.3$ & 0.59 & 20.12 & 110 & 0.0005 \\
E5 & $0.019 \pm 0.005$ & $-2.3 \pm 3.3$ & 0.45 & 11.46 & 110 & 0.0044 \\
E1 (A) & $0.064 \pm 0.0095$ & $-29.7 \pm 5.9$ & 0.9780 & 44.5 & 163 & 0.0089 \\
E2 (A) & $0.039 \pm 0.007$ & $-16.4 \pm 4.4$ & 0.9670 & 29.3 & 163 & 0.0035 \\
E3 (A) & $0.084 \pm 0.016$ & $-38.7 \pm 10.2$ & 0.9623 & 25.5 & 163 & 0.0150 \\
\hline
\end{tabular}

(A) Playback experiments with natural as well as artificially modified EOD duration, linear regression line without EODs that evoked no reaction; $r^{2}$, variance; $p$, probability of mistakenly rejecting the null hypothesis of a regression line slope equalling zero.

Table 1). Attack rates varied individually between $7 \pm 3.1$ for experimental subject E3 and $22 \pm 2.7$ bites /30 s for E2 at the same stimulus EOD pulse duration $(470 \mu \mathrm{s})$. However, independent of the individual aggression level, in every experimental subject aggression increased with increasing EOD duration (Table 1).

\section{Attack rate evoked by EODs of artificially modified duration}

The relationship between stimulus EOD duration and aggression detailed above also held for a single, pre-recorded EOD the duration of which was artificially varied ( $213 \mu \mathrm{s}, 300 \mu \mathrm{s}, 550 \mu \mathrm{s}, 765 \mu \mathrm{s}$; Figure 4F). The original EOD (of $498 \mu$ s that was also used unmodified for stimulation) had been recorded from a male $M$. macrolepidotus that was unfamiliar to all experimental subjects.

None of the three experimental subjects responded to an EOD of artificially reduced duration (213 $\mu$ s and $300 \mu \mathrm{s})$. Whereas the unmodified EOD of $498 \mu$ s evoked weak responses in all three fish, the EODs of increased duration, especially the longest one, evoked very strong responses. Compared to the original EOD, and depending on the experimental subject, attack rate increased from 6- to 25 fold when stimulus EOD duration was $765 \mu \mathrm{s}(53 \%$ longer than that of the original EOD of $498 \mu$ s duration). Starting from the unmodified EOD, aggression increased with EOD duration in similar fashion as shown for a range of natural, unmodified EODs ( $p<0.01$; Table 1$)$. 


\section{Neighbour-stranger comparisons}

According to 'dear enemy' theory, a fish is expected to respond less aggressively to a familiar neighbour's than to a stranger's EODs. Our null hypothesis deals with each fish separately; it predicts that an individual fish's response to familiar and unfamiliar EODs will be the same (no difference). In this series of experiments, stimulus EODs pre-recorded from an experimental subject's familiar neighbours were contrasted with EODs from stranger fish. We tested whether attack rates evoked by an active dipole playing back EODs differed between EODs used: either familiar neighbours' or strangers' EODs.

In all five experimental subjects, playback of a familiar neighbour's EOD evoked significantly lower attack rates than expected for an unfamiliar EOD of the same duration (Table 2). Non-overlapping 95\% confidence intervals for familiar playback EODs, compared with expected intervals for unfamiliar EODs, confirmed this result in each fish independently (Figure 4A-E). In experimental subject E3, the long duration of its neighbour's EOD made extrapolation necessary (Figure 4C). The extrapolation to an EOD duration of $620 \mu$ s appears acceptable in view of Figure 4D and E, where natural stimulus EODs of still greater duration were used. Pooling of the data for all fish was not permitted because the level of aggression evoked differed widely between individuals (as can hardly be expected otherwise). We therefore used each individual as its own control.

\section{Location of playback dipole}

We asked whether an experimental subject's attack rate evoked by playback of its neighbour's EODs depended on from which side, 'correct' or 'incorrect', it was stimulated. Had the experimental subjects and their neighbours been kept in the same tank for 1-4 weeks only, two out of three experimental subjects did not show any difference in attack rate $(p>0.1$, two-tailed unpaired $t$-test, $N=55$; Figure 5), whereas one did ( $p \leqslant 0.036$, two-tailed unpaired $t$-test, $N=55$ ). However, this fish's stronger response to neighbour B's switch of position was offset by the opposite result to neighbour A's position change.

When the experimental subjects and their neighbours had been kept in the same tank for two months or more, playback from a neighbour's opposite, 'incorrect' boundary evoked consistently stronger attack rates than from the 


\section{Fish E1}

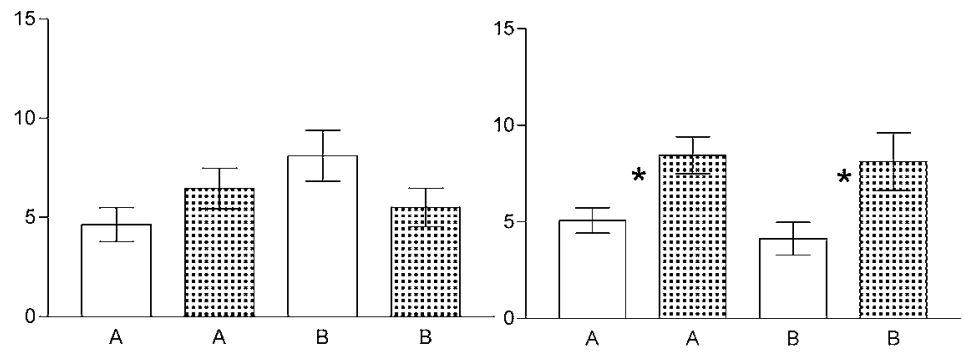

\section{Fish E2}
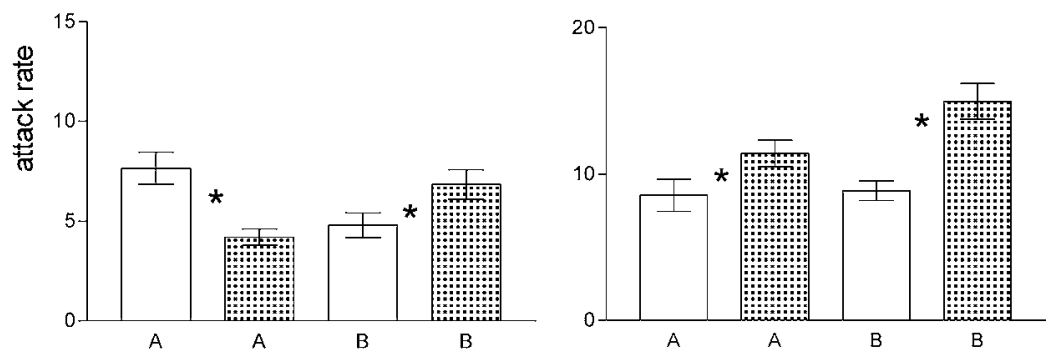

\section{Fish E3}
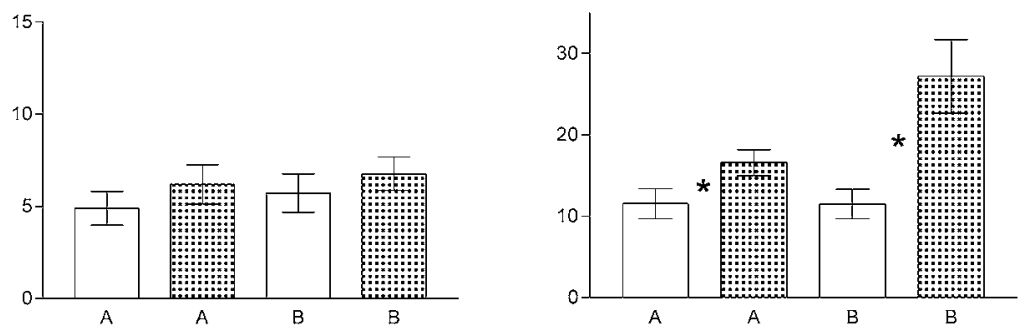

regular side $\quad$ mepposite side

Figure 5. Rates of attack (butts/30 s) on a dipole model of experimental subjects E1, E2, and E3 evoked by the playback of EODs recorded from neighbouring males (A and B) that were presented either from the 'regular', common territorial boundary (white columns), or from the opposite territorial boundary (filled columns). Fish had been in the same tank for either one to four weeks (left panel), or two to five months (right panel). Means with \pm 1 standard errors. Asterisks indicate significant differences at $p<0.05 ; N=55$ tests per fish and data point. 
Table 2. Comparison of observed attack rates, evoked by familiar EODs, with expected attack rates for unfamiliar EODs of the same duration, for experimental subjects E1-E5

\begin{tabular}{lccccc}
\hline Exp. subject & E1 & E2 & E3 & E4 & E5 \\
\hline Observed (familiar) & $9.1 \pm 2.7$ & $8.7 \pm 2.5$ & $2.2 \pm 1.1$ & $1.0 \pm 0.49$ & $1.86 \pm 0.98$ \\
Expected (unfamiliar) & $16.2 \pm 2.5$ & $20.51 \pm 2.1$ & $9.5 \pm 4.2$ & $10.7 \pm 2$ & $10.3 \pm 2.0$ \\
$t^{1}$ & 8.688 & 14.35 & 7.516 & 12.55 & 9.975 \\
df & 38 & 38 & 38 & 12 & 12 \\
$p$ & $<0.0001$ & $<0.0001$ & $<0.0001$ & $<0.0001$ & $<0.0001$ \\
\hline
\end{tabular}

${ }^{1}$ unpaired $t$-test (two-sided).

$N=20$ per playback EOD (experimental subjects E1-E3).

$N=7$ per playback EOD (E4 and E5).

regular, 'correct' boundary ( $p<0.05$, two-tailed unpaired $t$-test, $N=55$; Figure 5). Males showed differential behaviour (in the expected direction) even when the playback EODs were so similar that their negative phases differed by only $9 \mu$ s (see EOD waveforms for neighbours N1 and N2; Figure 2).

\section{Discussion}

A high degree of intraspecific variability in male EOD waveform seems to be typical for the genus Marcusenius, as confirmed in Marcusenius senegalensis (Scheffel \& Kramer, 1997), in the South African form of M. macrolepidotus that was used in the present study (Kramer et al., 1998, in prep.), and still more so in the Upper Zambezi form of M. macrolepidotus (Kramer, 1997a, b). Our study suggests two functions for EOD variability in males: (1) a wide range of EOD durations may facilitate intrasexual competition between males, and (2) allow discrimination between neighbours and strangers. Additionally, variability in male traits in a genus or a family seems to facilitate the evolution of a sexual dimorphism in some of its members (Burkhardt $\&$ de la Motte, 1987). The sexually dimorphic Upper Zambezi form of $M$. macrolepidotus, and the less advanced South African form studied in the present paper, are examples for this rule (Kramer, 1997a, b). 


\section{Dependency of attack rate on EOD duration}

An EOD of long pulse duration may indicate a high fighting potential in a male fish, because in the South African form of M. macrolepidotus studied in the present paper, EOD pulse duration increased weakly, but significantly with size in males (Kramer et al., 1998, in prep.). Therefore, playback EODs of long duration should represent a greater threat to a territory owner, and evoke more intense aggression, than EODs of short duration. Our experimental subjects behaved as expected, and attack rate increased with EOD duration over the full range of our field-recorded EODs (up to $975 \mu$ s duration). This result suggests that the high variability of male EODs in our fish is related to intrasexual selection.

Male communication signals are often used in the assessment of a rival. In the croaking gourami Trichopsis vittata the vocalisations generated by winners differed from those of losers by a higher sound pressure level and a lower dominant frequency, both of which were correlated with body weight (Ladich, 1998). Also in frogs, toads (Davies \& Halliday, 1978; Robertson, 1986; Wagner, 1989) and red deer (Clutton-Brock \& Albon, 1979), physical features of threatening calls (Reby \& McComb, 2003) are used by rivals to avoid useless fighting.

The reason why our experimental fish subjects seemed prepared for escalating so readily, independent of their own size, may be related to the protection from the plastic mesh barrier so that none of the experimental subjects had the experience of loosing a fight.

A high inter-individual variability in communication signals may serve different functions even in the same species. In damselfish, for example, males discriminate territorial rivals by their individually distinct vocalisations (Myrberg \& Riggio, 1985) whereas females use these signals so select mates (Myrberg et al., 1993). In M. macrolepidotus it is unknown whether there is female choice based on EOD waveform.

\section{'Dear enemy' phenomenon}

Playback EODs from neighbours and strangers evoked differential responses both in the South American gymnotiform Gymnotus carapo (McGregor \& Westby, 1992), and in all experimental subjects of the African mormyrid, $M$. macrolepidotus, that were studied in the present paper. In both fish, strangers' 
EODs evoked a stronger rate of aggressive responses than familiar neighbours' EODs. In both studies, cues from the individually distinct EOD pulse waveform alone were sufficient to evoke a change in behaviour. In the present study an additional relationship, not seen in the gymnotiform study, emerged: attack rate increased with EOD pulse duration. Our results in M. macrolepidotus are consistent with the high discrimination performance demonstrated among intraspecific natural and artificial EODs in Pollimyrus adspersus using the 'conditioned discrimination' method (Graff \& Kramer, 1992; Paintner \& Kramer, 2003).

As the 'dear enemy' phenomenon is thought to be based upon the relative threat presented by neighbours versus strangers (Temeles, 1994), our results suggest territoriality in male $M$. macrolepidotus. At least temporal territoriality in this species was suggested by intense male-male interactions observed in large aquaria (Werneyer \& Kramer, 2002). Further support comes from reproduction behaviour observed in aquarium. For spawning, the female visits the male's territory repeatedly over many hours in one night (Werneyer \& Kramer, in press). This is similar to the only other mormyrid species whose reproductive behaviour has been studied in detail, Pollimyrus adspersus (Crawford et al., 1986; Kirschbaum, 1987; Bratton \& Kramer, 1989). Therefore we can state that in the context of a reliable neighbourhood Marcusenius macrolepidotus males are able to establish a 'dear enemy' relationship.

Our results suggest that male $M$. macrolepidotus identify their neighbours individually by EOD waveform, however, we can neither exclude additional EOD cues, such as inter-discharge interval patterns, nor chemical, acoustical, or visual cues in the natural situation. Natural EODs provide sufficient intraspecific variability for making possible the discrimination between large numbers of individuals (Bratton \& Kramer, 1988; Paintner \& Kramer, 2003). Conditions remaining constant, long- and short-term stability of EOD waveform has been demonstrated (Kramer \& Westby, 1985; Bratton \& Kramer, 1988; Crawford, 1991), supported by a low $Q_{10}$ minimising temperature effects (Kramer \& Westby, 1985), and by the capacity of rapid impedance matching of the electric organ even when water conductivity changes drastically (Kramer \& Kuhn, 1993). The long time it took in our experiments for a differential response to a neighbours' EODs to evolve may indicate a very slow increase in readiness for reproduction, perhaps brought about by mutual electrical, visual, acoustic, or tactile stimulation, activating the pituitary-gonad axis. 


\section{Conclusion}

Intraspecific variability in male EOD waveform seems to have at least two functions in intrasexual selection in M. macrolepidotus (South African form): (1) to signal fighting potential, since the level of aggression evoked increased with duration of playback EODs; (2) to facilitate the discrimination between neighbours and strangers, which reduces useless fights.

The comments of ten Cate et al. (2002) on evolution of bird song largely apply also here. According to these authors, four criteria should be met for evolution of a communication signal, such as EOD, to be influenced by male competition so that they are related to quality: (i) interindividual variation in EOD waveform should be present, (ii) the variation should correlate to competitive ability (e.g., size), (iii) some variants of the signal can only be produced by males with the highest competitive ability, and (iv) receivers, in this case males, should differentiate their responses according to the rivals' communication signals. All these preconditions are met in M. macrolepidotus (South African form) - except perhaps (iii), if variants are meant to be qualitative. Therefore, we conclude that evolution of EOD duration is greatly influenced by intrasexual selection.

We do not yet know whether or not male EOD variability is also supported by female choice in M. macrolepidotus (South African form). In any case, 'runaway' selection for EODs of still longer duration appears to be limited by electroreceptive predators like the sharptooth catfish, Clarias gariepinus. This fish detects long-duration EODs ( $>2 \mathrm{~ms}$ ), as generated by male M. macrolepidotus from the Upper Zambezi (Hanika \& Kramer, 1999, 2000). Accordingly, bulldogs from the Okavango/Upper Zambezi River system are heavily preyed upon by $C$. gariepinus and other catfish (Merron, 1993; Winemiller \& Kelso-Winemiller, 1994). In contrast, bulldogs from South Africa with male EODs of much shorter duration (up to $880 \mu \mathrm{s}$ in our study, which is below the detection threshold of $C$. gariepinus) have not been found to form part of C. garipienus' diet (Bruton, 1979). Consequently, South African bulldogs seem to have found a way to use their communication signals in male-male competition without alerting predatory catfish, unlike their cousins from the Upper Zambezi. 


\section{Acknowledgements}

We would like to thank Dr. F.H. van der Bank (Rand Afrikaans University, Auckland Park, South Africa) and Dr. J. Engelbrecht (Mpumalanga Parks Board, South Africa) for sampling and exporting our fish. S.H. thanks Dr. H. Walter (Mathematics Department) for statistical advice, and Dr. H. Knüttel for setup-oriented computer programs and helpful comments on an earlier version of the manuscript. S. Lang and Dr. A. Scheffel recorded the interdischarge interval pattern used for the stimulation experiments. Supported by a grant of the Hochschulsonderprogramm III of the University of Regensburg to S.H., and the Deutsche Forschungsgemeinschaft (Kr 446/11-1/2) to B.K. All fish were captured and exported by, or in close collaboration with, Mpumalanga Parks Board (who granted permits and gave permissions to export live fish). The work presented here complies with current regulations covering experimentation and care of animals in Germany.

\section{References}

Bauer, R. \& Kramer, B. (1974). Agonistic behaviour in mormyrid fish: latency-relationship between the electric discharges of Gnathonemus petersii (Mormyridae). — Experientia 30: 51-52.

Bratton, B.O. \& Kramer, B. (1988). Intraspecific variability of the pulse-type discharges of the African electric fishes, Pollimyrus isidori and Petrocephalus bovei (Mormyridae, Teleostei) and their dependence on water conductivity. — Exp. Biol. 47: 227-238.

Bratton, B.O. \& Kramer, B. (1989). Patterns of the electric organ discharge during courtship and spawning in the mormyrid fish Pollimyrus isidori. - Behav. Ecol. Sociobiol. 24: 349-368.

Bruton, M.N. (1979). The food and feeding behaviour of Clarias gariepinus in Lake Sibaya, South Africa, with emphasis on its role as a predator of cichlids. — Trans. Zool. Soc. London 35: 47-114.

Burkhardt, D. \& de la Motte, I. (1987). Physiological, behavioural, and morphometric data elucidate the evolutive significance of stalked eyes in Diopsidae (Diptera). — Entomol. General. 12: 221-233.

Carlson, B.A. (2002). Electric signalling behaviour and the mechanisms of electric organ discharge production in mormyrid fish. - J. Physiol. (Paris) 96: 405-420.

Chellappa, S. \& Huntingford, F.A. (1989). Depletion of energy reserve during reproductive aggression in male three-spined stickleback, Gasterosteus aculeatus L. - J. Fish Biol. 35: 315-316.

Clutton-Brock, T.H. \& Albon, S.D. (1979). The roaring of red deer and the evolution of honest advertisment. - Behaviour 69: 145-169.

Cochran, W.G. \& Cox, G.H. (1968). Experimental designs ( $2^{\text {nd }}$ edn). - Wiley \& Sons, New York.

Crawford, J.D. (1991). Sex recognition by electric cues in a sound-producing mormyrid fish Pollimyrus isidori. - Brain Behav. Evol. 38: 20-38.

Crawford, J.D. (1992). Individual and sex specifity in the electric organ discharges of breeding mormyrid fish (Pollimyrus isidori). - J. Exp. Biol. 164: 79-102.

Crawford, J.D., Hagedorn, M. \& Hopkins, C.D. (1986). Acoustic communication in an electric fish Pollimyrus isidori, Mormyridae. - J. Comp. Physiol. A 159: 297-310. 
Davies, N.B. \& Halliday, T.R. (1978). Deep croaks and fighting assessment in toads Bufo bufo. - Nature 274: 683-685.

Fisher, J.B. (1954). Evolution and bird sociality. — In: Evolution as a process (Huxley, J., Hardy, A.C. \& Ford, E.B., eds). Allen \& Unwin, London, p. 71-83.

Graff, C. \& Kramer, B. (1992). Trained weakly electric fishes, Pollimyrus isidori and Gnathonemus petersii (Mormyridae, Teleostei), discriminate between waveforms of electric pulse discharges. — Ethology 90: 279-292.

Hanika, S. \& Kramer, B. (1999). Electric organ discharges of mormyrid fish as a possible cue for predatory catfish. - Naturwissenschaften 86: 286-288.

Hanika, S. \& Kramer, B. (2000). Electrosensory prey detection in the African sharptooth catfish Clarias gariepinus (Clariidae), of a weakly electric mormyrid fish, the bulldog (Marcusenius macrolepidotus). — Behav. Ecol. Sociobiol. 48: 218-228.

Hare, J.F. (1994). Colony member discrimination by juvenile Columbian ground squirrels (Spermophilus columbianus). - Ethology 92: 301-315.

Hepper, P.G. (1991). Kin recognition. — Cambridge University Press, Cambridge.

Höjesjö, J., Johnsson, J.I., Petersson, E. \& Järvi, T. (1998). The importance of being familiar: Individual recognition and social behavior in sea trout (Salmo trutta). - Behav. Ecol. 9: 445-451.

Johnsson, J.I. (1997). Individual recognition affects aggression and dominance relations in rainbow trout, Oncorhynchus mykiss. - Ethology 103: 267-282.

Kirschbaum, F. (1987). Reproduction and development of the weakly electric fish Pollimyrus isidori (Mormyridae, Teleostei) in captivity. — Env. Biol. Fish. 20: 11-31.

Kramer, B. (1978). Spontaneous discharge rhythms and social signalling in the weakly electric fish Pollimyrus isidori. - Behav. Ecol. Sociobiol. 4: 61-74.

Kramer, B. (1979). Electric and motor responses of the weakly electric fish Gnathonemus petersii (Mormyridae) to play-back of social signals. - Behav. Ecol. Sociobiol. 6: 6779.

Kramer, B. (1990). Electrocommunication in teleost fishes: behavior and experiments. Springer, Berlin.

Kramer, B. (1996). Electroreception and communication in fishes. - Gustav Fischer, Stuttgart.

Kramer, B. (1997a). A field study of African elephantfish (Mormyridae, Teleostei): electric organ discharges in Marcusenius macrolepidotus (Peters, 1852) and Petrocephalus catostoma (Günther, 1866) as related to sex. - J. Afr. Zool. 111: 313-341.

Kramer, B. (1997b). Electric organ discharges and their relation to sex in mormyrid fish. Naturwissensch. 84: 119-121.

Kramer, B. \& Kuhn, B. (1993). Electric signalling and impedance matching in a variable environment: the electric organ of a mormyrid fish actively adapts to changes in water conductivity. - Naturwissensch. 80: 43-46.

Kramer, B. \& Van der Bank, F.H. (2000). The southern churchill, Petrocephalus wesselsi, a new species of mormyrid from South Africa defined by electric organ discharges, genetics, and morphology. - Environ. Biol. Fishes 59: 393-413.

Kramer, B., Van der Bank, F.H. \& Skelton, P.H. (1998). Two new species of snoutfish (Mormyridae) from South Africa: evidence from electric organ discharges. — Paradi Conference, Grahamstown (RSA), p. 50.

Kramer, B. \& Westby, G.W.M. (1985). No sex difference in the waveform of the pulse type electric fish, Gnathonemus petersii (Mormyridae). — Experientia 41: 1530-1531. 
Kramer, B. \& Weymann, D. (1987). A microprocessor system for the digital synthesis of pulsed and continuous discharges of electric fish (or animal vocalizations). - Behav. Brain Res. 23: 67-174.

Ladich, F. (1998). Sound characteristics and outcome of contests in male croaking gouramis (Teleostei). — Ethology 104: 517-529.

Leiser, J.K. \& Itzkowitz, M. (1999). The benefits of dear enemy recognition in threecontender convict cichlid (Cichlasoma nigrofasciatum). — Behaviour 136: 983-1003.

Lücker, H. \& Kramer, B. (1981). Development of sex difference in the preferred latency response in the weakly electric fish, Pollimyrus isidori (Cuvier et Valenciennes)(Mormyridae, Teleostei). — Behav. Ecol. Sociobiol. 9: 103-109.

McGregor, P.K. \& Westby, G.W.M. (1992). Discrimination of individually characteristic electric organ discharges by a weakly electric fish. - Anim. Behav. 43: 977-986.

Merron, G.S. (1993). Pack-hunting in two species of catfish, Clarias gariepinus and $C$. ngamensis in the Okavango Delta, Botswana. - J. Fish Biol. 43: 575-584.

Moller, P. (1995). Electric fishes. History and behavior. - Chapman and Hall, London.

Morris, M.R., Gass, L. \& Ryan, M.J. (1995). Assessment and individual recognition of opponents in the pygmy swordtails Xiphophurus nigrensis and X. multilineatus. Behav. Ecol. Sociobiol. 37: 303-310.

Myrberg, A.A. \& Riggio, R.J. (1985). Acoustically mediated recognition by a coral reef fish (Pomacentrus partitus). - Anim. Behav. 33: 411-416.

Myrberg, A.A., Ha, S.J. \& Shamblott, M.J. (1993). The sounds of bicolor damselfish (Pomacentrus partitus), Predictors of body size and spectral basis for individual recognition and assessment. - J. Acoust. Soc. Am. 94: 3067-3070.

Paintner, S. \& Kramer, B. (2003). Electrosensory basis for individual recognition in a weakly electric, mormyrid fish, Pollimyrus adspersus (Günther, 1866). — Behav. Ecol. Sociobiol. 55: 197-208.

Peeke, H.V.S., Herz, M.J. \& Gallagher, J.E. (1971). Changes in aggressive interaction in adjacently territorial convict cichlids (Cichlasoma nigrofasciatum), a study of habituation. - Behaviour 37: 43-54.

Reby, D. \& McComb, K. (2003). Anatomical constraints generate honesty: Acoustic cues to age and weight in the roars of red deer stags. - Anim. Behav. 65: 519-530.

Robertson, J.G.M. (1986). Female choice, male strategies and the role of vocalization in the Australian frog Uperoleia rugosa. — Anim. Behav. 34: 773-784.

Scheffel, A. \& Kramer, B. (1997). Electrocommunication and social behaviour in Marcusenius senegalensis (Mormyridae, Teleostei). — Ethology 103: 404-420.

Scheffel, A. \& Kramer, B. (2000). Electric signals in the social behavior of sympatric elephantfish (Mormyridae, Teleostei) from the Upper Zambezi River. - Naturwissensch. 87: 142-147.

Scheffel, A. \& Kramer, B. (in press). Intra- and interspecific electrocommunication among sympatric mormyrids in the Upper Zambezi River. - In: Communication in fishes (Ladich, F., Collin, S.P., Moller, P. \& Kapoor B.G., eds). Science Publishers, Enfield.

Schluger, J.H. \& Hopkins, C.D. (1987). Electric fish approach stationary signal sources by following electric current lines. — J. Exp. Biol. 130: 359-367.

Taverne, L. (1971). Note sur la systématique des poissons Mormyriformes. Le probème des genres Gnathonemus Gill, Marcusenius Gill, Hippopotamyrus Pappenheim, Cyphomyrus Myers et les nourveaux genres Pollimyrus et Brienomyrus. - Rev. Zool. Bot. Afr. 84: 99-110. 
Temeles, E.J. (1994). The role of neighbours in territorial systems: when are they 'dear enemies'? - Anim. Behav. 47: 339-350.

ten Cate, C., Slabbekoorn, H. \& Ballintijn, M. (2002). Birdsong and male-male competition: causes and consequences of vocal variability in the collared dove (Streptopelia decaocto). - Adv. Study Behav. 31: 31-75.

Teyssèdre, C. \& Serrier, J. (1986). Temporal spacing of signals in communication, studied in weakly electric fish (Teleostei, Pisces). — Behav. Proc. 12: 77-98.

Thorpe, E.K., Taylor, A.C. \& Huntingford, F.A. (1995). How costly is fighting? Physiological effects of sustained exercise and fighting in the swimming crab, Necora puber (L.) (Brachyura, Portunidae). — Anim. Behav. 33: 965-984.

Turner, R.W., Maler, L. \& Burrows, M. (1999). Electroreception and electrocommunication. - J. Exp. Biol. 202.

Wagner, W.E.J. (1989). Fighting, assessment, and frequency alteration in Blanchard's cricket frog. - Behav. Ecol. Sociobiol. 25: 429-436.

Werneyer, M. \& Kramer, B. (2002). Intraspecific agonistic interactions in freely swimming mormyrid fish, Marcusenius macrolepidotus (South Africa form). - J. Ethology 20: 107-121.

Werneyer, M. \& Kramer, B. (in press). Electric signalling and reproductive behaviour in a mormyrid fish, the bulldog Marcusenius macrolepidotus (South African form). J. Ethol.

Winemiller, K.O. \& Kelso-Winemiller, L.C. (1994). Comparative ecology of the African pike, Hepsetus odoe, and tigerfish, Hydrocynus forskahlii, in the Zambezi River floodplain. - J. Fish Biol. 45: 211-225.

Ydenberg, R.C., Giraldeau, L.A. \& Falls, J.B. (1988). Neighbours, strangers, and the asymmetric war of attrition. - Anim. Behav. 36: 343-347. 